\title{
Social Protection for Transformation
}

\section{Rachel Sabates-Wheeler and Stephen Devereux}

\begin{abstract}
1 Introduction
The social protection response to the safety nets agenda, which was justifiably criticised as narrow in its vision and residualist in its implementation, bifurcates according to the vision of how long-term and sustainable poverty reduction will be achieved. One vision sees risk management as explicitly linked with economic growth, the argument being that reducing risk or protecting the poor against income and consumption variability will allow them to invest and accumulate - a 'trampoline' out of poverty (World Bank 2000). The other vision, the one that we promote and develop here, argues that fundamental to long-term poverty reduction is a positive relationship between livelihood security and enhanced autonomy or empowerment. While understandings of 'poverty' have moved to incorporate social dimensions of wellbeing together with rights-based approaches, social protection continues to be conceptualised by many development agencies mainly in terms of public responses to livelihood shocks - the conventional economic 'safety net' function. But this is 'economic protection', not 'social protection', and it is hardly socially transformative. Largely missing from risk management frameworks, for instance, is any concern for equity and social rights. We argue that an appreciation of this second linkage can help to create the policy conditions for a virtuous cycle of pro-poor growth, governance systems that are accountable and responsive to poorer as well as wealthier citizens, and an approach to development that is grounded in concerns for social justice.
\end{abstract}

The 'transformative social protection' approach emerges from a broader conceptualisation of vulnerability than economic risk alone; one that is based instead on an appreciation of structural inequalities. Attempting to address structural vulnerabilities (together with other forms) requires taking a political approach to social protection, focusing on rights, duties, democracy and advocacy. This article describes what we mean by the 'transformative' potential of social protection and concludes by asserting the case for social protection as supporting social as well as economic goals of development.

\section{Reconceptualising vulnerability}

Vulnerability can be conceptualised in a variety of ways, depending critically on the unit of analysis and the source of risk. Income, consumption and assetbased understandings of vulnerability underpin the majority of government and donor approaches to vulnerability. For this reason, we see many agencies taking an instrumentalist approach to social protection policies, as a collection of measures to manage risk and thus improve or protect livelihoods, by stabilising income and consumption or building up assets. Within many risk management frameworks, vulnerability is attributed to the characteristic of a person or group, an event affecting a person or group, or a stage in a person's lifecycle. For instance, people living with disabilities can be characterised as 'more' or 'less' vulnerable than people living without disabilities in any given context. This type of analysis tends to classify vulnerability according to a range of risks or shocks that affect one or more of a variety of livelihood assets (World Bank 2000: 136-8). This is reflected in the range of policy instruments proposed, such as reception centres for orphans, shelters for domestically abused women, disability aids for farmers living with disabilities, strategic grain reserves, and various social assistance programmes (World Bank 2000: 141).

If, rather than focusing on risk as an exogenous factor to be 'managed', vulnerability was conceptualised as emerging from and embedded in the sociopolitical context, then our attention would 
no longer be focused on how to design a policy so that various groups face less risk in a given context, but on how to transform this context to minimise risk for a range of vulnerable groups (Sabates-Wheeler and Waite 2003)

The dominant policy agenda around social protection is almost exclusively concerned with measures and programmes that stabilise expectations of risk, without affecting the fundamental causes of vulnerability, which are embedded in social and political relations at all levels. For instance, the Social Risk Management (SRM) framework mainly addresses economic risks to household incomes and assets (World Bank 2000: 138; see also Holzmann and Kozel, this IDS Bulletin). Absent from this framework are 'social risks' that also contribute to poverty and the construction of vulnerability. This is evidenced by the way in which social inclusion, social cohesion and social stability are treated as positive externalities of well-designed 'social risk management' interventions.

Social risks may be categorised as 'structural' or 'contingent'. Structural risk refers to situations where groups or individuals are marginalised or discriminated against, and by its nature has longerterm implications for poverty and vulnerability than contingent risk, which is a function of environmental or economic factors, such as an earthquake, or hyper-inflation. Because dominant risk management frameworks are largely focused on income or consumption variability, with other (especially social) dimensions of vulnerability being effectively overlooked, we argue that they do not incorporate a comprehensive understanding of vulnerability, and are therefore limited in the scope and purpose of the social protection provisions they advocate.

Relocating an understanding of 'vulnerability' in sociopolitical space necessarily conjures up linkages to large literatures on social exclusion, rights-based approaches, citizenship and power (Kabeer 2002; 2005; Gaventa 2004; Nyamu-Musembi and Cornuall 2004). These literatures are not reviewed here. However, in accordance with the general thrust of this literature, we would argue that, like the rightsbased approach or an agenda for inclusive citizenship, a transformative approach holds little meaning if it is unable to achieve a positive change in power relations among various stakeholders - development actors, government agencies, differentiated socioeconomic groups, different household members. Thus, a vision of transformative social protection, 'must be interrogated for the extent to which it enables those whose lives are affected to articulate their priorities and claim genuine accountability' from different implementing and 'provisioning' stakeholders (Nyamu-Musembi and Cornwall 2004)

\section{Introducing the transformative element to social protection}

If social protection needs are defined in a narrow 'safety net' sense, as mechanisms for smoothing consumption in response to declining or fluctuating incomes, then the focus of interventions will logically be on targeted income or consumption transfers to affected individuals. In our view, the range of social protection interventions should extend well beyond social transfers - and the resources transferred should be broader than cash or food, to include redistribution of assets that will reduce dependency on handouts and enable at least some poor people to achieve sustainable livelihoods. Targeted social transfers provide 'economic protection' in response to economic risks and livelihood vulnerability. Other forms of 'social protection' would address distinct problems of 'social vulnerability', not necessarily through resource transfers, but by delivering appropriate social services and implementing measures to modify or regulate behaviour towards socially vulnerable groups.

\section{Strategies to deal with problems of social} vulnerability require a transformative element, where 'transformative' refers to the pursuit of policies that integrate individuals equally into society, allowing everyone to take advantage of the benefits of growth, and enabling excluded or marginalised groups to claim their rights. For instance: support to trade unions may enable socioeconomically disempowered workers to claim their rights to decent working conditions; facilitation and creation of spaces for deliberative democratic processes can increase citizen participation; sensitisation and awareness campaigns can transform public attitudes and behaviour; and changes to the regulatory framework could protect vulnerable or minority groups against discrimination and abuse.

Another sphere where transformative social protection interventions may be needed is in the intra-household division of resource ownership, 
access and use. For instance, many difficulties involved in the provision of social protection for women relate to sociocultural values and practices that leave women in particularly vulnerable positions. Clearly, social protection instruments designed for many categories of women must include a substantial 'transformative' element, in the sense that power relations between men and women become more balanced. Appropriate legislation may be necessary (for instance, to outlaw practices that perpetuate gross discrimination and bad treatment of women and girls), but this goes only a small way to changing sociocultural values. Efforts could focus on educating both men and women about their rights and how to access their rights. Other political and institutional constraints facing women relate to: lack of access to the legal system; cultural resistance to changes in gender relations; and commonly held beliefs about women's role in land management and property ownership.

Bearing the above points in mind, we propose the following definition of social protection, which incorporates but goes beyond transfer-based responses to economic risk and vulnerability:

Social protection describes all initiatives that transfer income or assets to the poor, protect the vulnerable against livelihood risks, and enhance the social status and rights of the marginalised; with the overall objectives of extending the benefits of economic growth and reducing the economic or social vulnerability of poor, vulnerable and marginalised people.

Operationalising this definition, social protection includes four categories of instruments: provision measures, which provide relief from deprivation; preventive measures, which attempt to prevent deprivation; promotive measures, which aim to enhance incomes and capabilities; and transformative measures, which seek to address concerns of social justice and exclusion.

- 'Provision' measures provide relief from deprivation. Provision measures are narrowly targeted safety net measures in the conventional sense. They include social assistance for the chronic poor, targeted resource transfers - disability benefit, single-parent grants, and social pensions that are financed publicly (out of the tax base, with donor support, or through NGOs) - social services for poor individuals and groups who need special care, including orphanages and reception centres for abandoned children, and the abolition of education and health charges to extend access to basic services to the very poor.

- Preventive measures seek to prevent deprivation, and deal directly with poverty alleviation. These measures include social insurance for 'economically vulnerable groups' - people who have fallen or might fall into poverty, and may need support to help them manage their livelihood shocks. Social insurance programmes refer to formalised systems of pensions, health insurance, maternity benefit and unemployment benefits, often with tripartite financing between employers, employees and the state. They also include informal mechanisms, such as savings clubs and funeral societies. Strategies of risk diversification - such as crop or income diversification - can also be considered as preventive measures.

- Promotive measures aim to enhance real incomes and capabilities, which is achieved through a range of livelihood-enhancing programmes targeted at households and individuals. The inclusion of promotive measures as a category here is open to the criticism that it takes social protection too far beyond its original conceptualisation. However, the intention is not to broaden the scope to include (potentially) all development initiatives, but to focus on promotive measures that have income stabilisation at least as one objective, or on social protection measures that have 'livelihood promotion' as well as 'livelihood protection' ambitions. Examples include microcredit that is invested in small enterprises in order to generate income, while also stabilising income and consumption, or public works projects that transfer food rations or cash wages, while simultaneously building economic infrastructure such as roads or irrigation.

- Transformative measures seek to address concerns of social justice and exclusion, such as the exploitation of workers, or discrimination against ethnic minorities. Transformative interventions include collective action for workers' rights, changes to the regulatory framework to protect 'socially vulnerable groups' (e.g. people with 


\section{Figure $1 \mathrm{~A}$ conceptual framework for social protection}

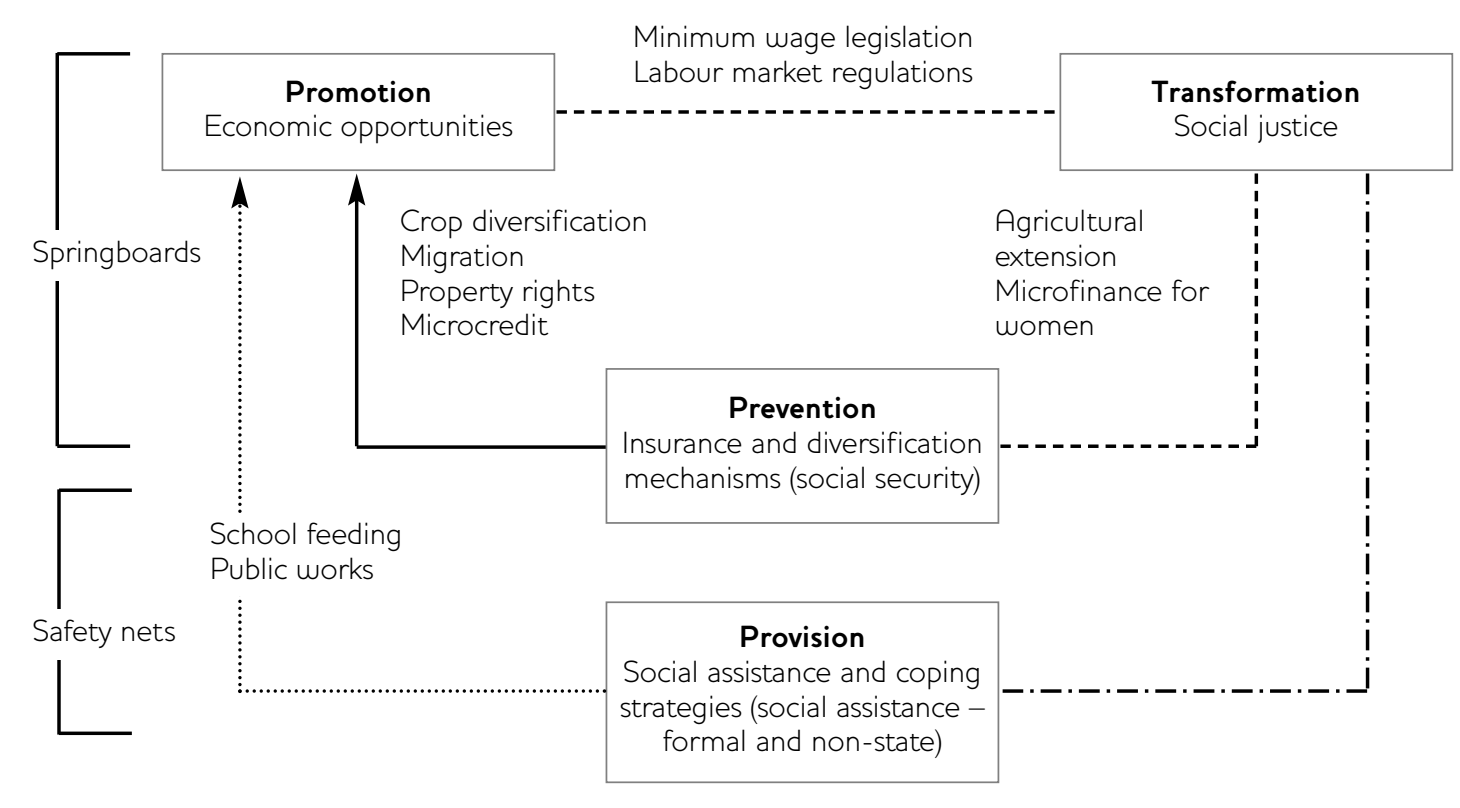

disabilities, or victims of domestic violence) against abuse, as well as sensitisation campaigns (such as the global 'HIV/AIDS Anti-Stigma Campaign') and advocacy to enhance social equity.

These categories may of course overlap, and many social protection interventions aim to achieve more than one objective. As noted, public works projects, school feeding schemes and microcredit programmes all strive at promoting incomes in the long term as well as preventing deprivation in the short term. Similarly, a 'transformative' measure such as eradicating labour market discrimination against $\mathrm{HIV}$-positive people is not only a victory for social justice, it also enhances the employment prospects of people living with HIV and AIDS.

Figure 1 illustrates the relationship between these categories and presents our conceptual framework for thinking about social protection. Reading from the bottom, 'provision' policies are essentially oldstyle 'safety nets', however if designed well, these instruments can have positive effects on the prevention of deprivation, livelihood promotion and even social transformation. The solid black line in the diagram indicates a strong and direct relationship. For instance, 'preventive' interventions, such as crop diversification to reduce agricultural risk, may also have 'promotive' outcomes in the sense that a wider crop portfolio may lead to a competitive market advantage. Most preventive mechanisms could be argued to have promotive effects, in fact, in the sense that risk reduction enables people to take advantage of opportunities that they would otherwise have been unable to do.

The top half of the diagram corresponds with instruments and policies that facilitate movements out of poverty, or 'springboards'. Broadly speaking, the lefthand side of Figure 1 corresponds to social protection interventions that have economic outcomes and direct growth effects, whereas the right-hand side represents social outcomes - the 'transformative' aspect of social protection. At the top of the diagram the economic and social dimensions come together and are interrelated. That is, by pursuing activities that overcome structural inequalities and injustice, people are better able to engage in society and the economy, which will have positive spin-offs both for their livelihoods and for economic growth. The dashed line connecting 'Promotion' and 'Transformation' illustrates both the interconnectedness of economic and social vulnerabilities, and the potential for interventions in either sphere to reduce both sources of vulnerability. This is especially true of vulnerabilities that are structural and chronic, rather than contingent and acute. 
The dashed lines indicate a less obvious or weaker relationship. For instance, some preventive mechanisms can be transformative, and vice versa, but this relationship is not strong, nor inevitable. One example is microfinance schemes that simultaneously provide both social insurance and economic opportunities, and often have positive knock-on effects by empowering individuals within their families, and households within their communities. Another weak relationship is illustrated by the dashed line from 'Provision' to 'Promotion', highlighting the possibility that certain safety net measures may build capabilities or assets, thereby enabling beneficiaries to take opportunities that would otherwise be denied to them. Similarly, some social protection instruments, such as minimum wage legislation, can be both promotive and transformative. Paying workers a fair wage enhances their incomes and capabilities, while the very process of bargaining with employers to raise and enforce the minimum wage - through trade unions or public campaigns - can be politically empowering, especially when supported by government.

Finally, the thick banded line linking 'Provision' and 'Transformation' indicates a potential negative relationship between the humanitarian objective of delivering social assistance, and social objectives such as human dignity and autonomy. Some social protection measures can have the unintended consequence of reinforcing established power hierarchies, or of being stigmatising and exacerbating social polarisation and exclusion. Examples include certain targeting mechanisms that are applied to social assistance programmes for 'vulnerable groups' (e.g. singling out 'AIDS orphans' from other vulnerable children, or requiring adults to declare their HIV status), or paying participants on public works with food rations rather than cash wages. One advantage of drawing attention to the social dimensions is that this confirms the need for thinking on social protection to move beyond oldstyle safety nets, and to ensure that social protection interventions have neutral or positive - rather than negative - social impacts.
It is important to re-emphasise that our expanded definition of social protection does not extend to all policy measures that promote livelihoods and economic growth. Instead, we highlight the potential of certain social protection measures to contribute to economic growth and productivity as well as to social equity, either through achieving both objectives simultaneously or through linkages with other interventions. A good example is school feeding schemes - a social protection intervention that stabilises food consumption but also enhances access to education for poor and socially excluded children, thus building their human capital and improving their lifetime earnings potential, through linkages with education services.

\section{Conclusion}

The transformative approach to social protection establishes a more positive and proactive role for social protection that extends its scope beyond its roots in residualist and often stigmatising social safety nets. There are other reasons for supporting the 'transformative' component of social protection. It also enables the identification of powerful synergies between the 'economic' (provision, prevention, promotion) and 'social' (transformation) functions performed by several social protection measures. $A$ transformative approach extends the definition of social protection beyond targeted income and consumption transfers that address chronic poverty and livelihood threats. Strategies to deal with social vulnerability must address the social injustice that arises from structural inequalities and abuses of power, and transformative social protection must aim to achieve empowerment, equity and the realisation of economic, social and cultural rights. If carefully selected to match the nature of vulnerability, social protection mechanisms can be both socially transformative and fiscally affordable - sensitisation campaigns cost much less than cash transfer programmes - while contributing to the policy goals of pro-poor economic growth and improved social equity. 


\section{References}

Gaventa, J. (2004) 'Towards Participatory

Governance: Assessing Transformative Possibilities', in S. Hickey and G. Mohan (eds), From Tyranny to

Transformation, London: Zed Books

Kabeer, N. (2005) 'The Search for Inclusive

Citizenship: Meanings and Expressions in an Inter-

Connected World', in N. Kabeer (ed.), Inclusive

Citizenship: Meanings and Expressions, London: Zed Books

Kabeer, N. (2002) 'Citizenship, Affiliation and Exclusion: Perspectives from the South', IDS

Bulletin 33.2
Nyamu-Musembi, C and Cornwall, A. (2004) What is the Rights Based Approach all About? Perspectives from International Development Agencies, IDS Working Paper 234, Brighton: IDS

Sabates-Wheeler, R. and Waite, M. (2003) Migration and Social Protection, Migration, Globalisation and Poverty Working Paper Series, Migration Centre, Sussex, December

World Bank (2000) World Development Report 2000/2001, Washington DC: World Bank 